\title{
Cost Management Practices in Collaborative Product Development Processes
}

\author{
Carlos Barbosa $^{1}$, Paulo Afonso ${ }^{2}$, and Manuel Nunes ${ }^{2}$ \\ ${ }^{1}$ Department of Polymer Engineering, University of Minho, Portugal \\ cbnuno@dep.uminho.pt \\ ${ }^{2}$ Production and Systems Department, University of Minho, Portugal \\ \{psafonso, lnunes\} @dps. uminho.pt
}

\begin{abstract}
This study aims at highlighting the current knowledge, practices and effects of collaborative and concurrent new product development processes in the framework of the Portuguese plastic processing industry. By means of a case study approach, the conditioning factors affecting the strategic collaborations among firms are systemized. Mutual dependence, trust, and extensive information sharing were identified as prerequisites factors for a better buyer-supplier interdependence and involvement, as well as for the overall benefit of the supply chain. Moreover, collaborative and concurrent new product development processes ask for the use of cost management practices and advanced technical specifications (standards) which emerge as technical and management tools to achieve higher levels of efficiency and quality at the lower cost. Practices such as target and kaizen costing, value engineering, and design-to-cost, were perceived to play a remarkable positive effect on the internal/external organizational boundaries.
\end{abstract}

Keywords: Cost Management, Inter-organizational Cost Management Practices, Collaborative Strategies, Buyer-Supplier Relationship, New Product Development.

\section{$1 \quad$ Introduction}

The production systems of the future must be observed in terms of very interlinked production chains. Companies have to take care of costs to meet the descending price rate of the market. Worldwide competition requires continuous productivity improvements and efficient cost control that lead firms assume internally narrow (strategic) competencies and extensive outsourcing. In this way, the interdependence among production partners within a network or supply chain has been increasing.

Such approach pushes to strategic alliances and other types of buyer-supplier cooperation that have led to profitable results [1]. In this context, high levels of interfirm trust can decrease the transaction costs of the relationship, thus providing competitive advantage for the partners. Furthermore, [2] advocate that the benefits of mutual inter-firm trust can be measurable in financial terms and suggest that managers should pay more attention to the role of inter-firm trust in partner selection 
processes. Open-book and other collaborative practices have been mentioned both as a means for improving the cost efficiency of supply chains and as a tool for building trust into customer-supplier relationships. Indeed, they can even support analysts to quantity incommensurable characteristics, such as inter-firm trust.

Many firms form alliances with their suppliers and customers that do not fit into the classical dichotomy of hierarchies and markets. One outcome of these hybrid relational forms is the development of cost management techniques that cross the organizational boundary between buyers and suppliers to reduce costs through collaborative efforts 3]. Thus, high levels of buyer-supplier collaboration not only assumes an exchange of technical knowledge and the synchronization of production flows across supply chain members but, also includes sharing sensitive cost information, which has been usually kept secret by business partners [4].

By means of a case study approach, this study underlines the current knowledge, practice and effects (benefits and detriments) of collaborative and concurrent practices in new product development (NPD) and tests the adherence of a set of conditioning factors within the Portuguese plastic processing industry.

\section{$2 \quad$ Literature Review}

Inter-Organizational Cost Management (IOCM) practices guide suppliers and buyers to find ways to collaboratively reduce costs during the NPD process and has been shown as a valuable "tool" to manage those systems and increase value to both buyers and suppliers, improving the overall performance of complex and multidisciplinary NPD projects and increasing the overall profits of the value chain.

IOCM can be defined as buyers' and suppliers' coordinated efforts to reduce costs through target costing, value engineering and design-to-cost among other techniques. Past research has primarily argued that such practices depend on component characteristics, relationship characteristics, and characteristics of the transaction. Agndal and Nilsson [5] reported that the deepest collaboration around IOCM issues and the greatest joint use of suppliers' cost information typically occurs in earlier activities in the exchange process, including supplier selection, joint product design and joint manufacturing process development.

In this context, collaborative and concurrent NPD processes ask for the use of a set of practices which emerge as technical and management tools for achieving high standards of efficiency and quality at the lower cost. Firms aiming at implementing this strategy effectively have to pay close attention to several contingency factors on the organizational level and properly manage supplier involvement on the product development process, as well as on the product industrialization and parts supplying at production stage.

Researchers agree on the importance of an alignment between cost management practices in supply chain management and new product development process. However, some view effective cost management practices in supply chain management as critical to successful NPD process while others perceive effective NPD process as critical to successful cost management practices in supply chain management [6-9]. 
In reality, IOCM practices and new product development process are complementary activities. A new product will be less than totally successful if it is not chain-friendly [10]. On the other hand, international supply chains are reliant on a continuous development of customer-friendly products to distribute efficiently around the globe [10]. Effective cost management practices in supply chain management, particularly in the case of coordinated supply networks, and effective collaborative NPD process should be regarded as cumulative capabilities, that is, they exist simultaneously in a mutually reinforcing fashion [11].

IOCM supply chains and collaborative NPD process share a number of characteristics including an emphasis on customer responsiveness, internal alignment as an elemental starting point, and the coordination of technological developments accomplished through the collective efforts of cross-functional teams representing a mixture of chain members. This movement depends on a combination of innovative organizational practices such as integrated collaborative NPD and coordinated supply networks [12].

The literature emphasizes that the use of IOCM practices results in high level of cost transparency in supply chains and increases overall profits [4, 5]. Several studies demonstrate the relevance of the relationship between effective NPD processes as critical to successful cost management practices in supply chain management [6-9].

\section{Case Study}

\subsection{Research Method}

Different sources of data gathering were used: direct observations and documentation analyses as well as open and semi-structured interviews following a predefined questions guide and research protocol (on average each open interview lasted 60 minutes).

Our approach was firstly to prepare the semi-structured guidelines document and send it to the respondents. Afterwards, we received the semi-structured guidelines replies from the respondents and, consequently, a carefully analyses was performed. The second step of our approach comprehended an open interview by teleconference in order to close the remained gaps from the first step and, additionally, to extend the discussion to practical examples/situations experienced by the companies during the product development process.

\subsection{Cases}

The focus of this study was on a set of three injection-moulding companies (suppliers) with know-how in NPD procedures. The companies, named hereafter as: PlasNetwork, IdeaMaker, and NextVision, are located in the central coast of Portuguese mainland.

These companies were chosen in order to gather important insights from different types of plastic injection moulding companies. While NextVision's activities are centred $100 \%$ in automotive industry, the PlasNetwork is still not supplying such kind 
of particular industry. On the other hand, IdeaMaker's activities are balanced between automotive (30\% to $40 \%)$ and other industries. Therefore, NextVision and IdeaMaker are 'supported' by the ISO/TS 16949 standards (among others), whereas the PlasNetwork holds the ISO 9001:2000 and ISO 14000:2004 registrations.

ISO/TS 16949:2002 uses ISO 9001:2000 as its base specification. It has a focus on customer satisfaction, being important for designing, implementing and maintaining the organization's quality management system. This standard implies greater attention to customer specific requirements and the organization's ability to satisfy them.

PlasNetwork is a company with ca. 60 employees that offers a set of transversal services within development, engineering, industrialization and production of plastic products and components. They have the knowledge of gathering and managing the competencies from several organisms: technological centres, mould makers, designers, laboratories, raw materials and equipment suppliers, etc. Working as the consultant centre of an entire network, this firm manages the entire product development process from the concept generation to the delivery of the product. The strongest capability of this company is to manage projects in a very flexible way.

IdeaMaker is a second tier supplier of automotive industry. Besides, they also supply package, houseware, and other industries. It is a company with ca. 15 employees divided by several inner activities such as project management, thermoplastics injection (e.g. over-moulding, insert-moulding), assembly lines, ultrasonic welding, quality control, and moulds manufacturing; other competencies, for instance, designing and computer-aided-engineering (CAE) as well as prototyping are outsourced. Interlinking skills throughout the production process provides customers monitoring and technical support until placing the product on the market.

NextVision is a much larger company than the previous described. It is a company with ca. 650 employees and its activities have been totally centred in Tier 1 (interior automotive components: centre console, air louvers, radio bezels, armrests, door trims, etc.) customers for about 20 years. Worldwide they are considered one of the major players in terms of air vents production. The company provides complete design, engineering, manufacturing and assembly operations for injection moulded interior subsystems. Other capabilities include painting, multiple interior surface decoration technologies, and an accredited testing laboratory along with a complete computer-aided-design (CAD)/CAE department with in-house rapid prototyping.

\section{$4 \quad$ Findings and Discussion}

PlasNetwork develops the initial ideas/concepts in parallel with customers. This process starts by deeply assessing the customer needs and the product specifications.

This integration (concurrent engineering) takes place earlier in the product development process with the purpose of reducing time-to-market as well as eliminating the probability of errors' propagation along the process.

"the competitive advantage of our activity is achieved by adding value through collaborative strategies [...] Such approach allows the company to be more agilethat might be tricky to manage [...] it must involve multiple partners as early as possible on the product development process" (PlasNetwork CEO) 
This company aims at holding the ISO/TS 16949 registration in order to supply the automotive industry in a near future. Meanwhile, they have been developing an internal methodology (roadmap) according to that ISO technical specification. Inputs from suppliers/customers are (value-added) perceived as improvements for this methodology. The procedures implemented by the automotive industry are considered, by the interviewed, as the best practices that all companies should follow.

In the non-automotive industry and when the collaboration with the customer is tight the supplier may contributes to redesign the proposed product. This kind of collaboration leads to deeper buyer-supplier relationship that is beyond the functional level, i.e. the collaboration is on an emotional (or co-creation) level meaning a higher confidence and mutual dependence.

IdeaMaker develops somehow the abovementioned approach for buyers from the non-automotive sector. Indeed, they look to their customer needs - rethinking optimizing them with high levels of productivity and innovation. The transfer of skills (collaboration) between partners allows them to offer to the global market better quality final product. As PlasNetwork, this company promotes with its nonautomotive customers a high level of collaborative strategies at the idea/concept generation phase in order to decrease/optimized costs for both parts. Furthermore, with a transparent cost breakdown approach the company seeks to build customer loyalty.

On the other hand, the product development process for the automotive first tier customers is quite different. Foremost, this industry obliges suppliers to hold the ISO/TS 16949 registration which is a powerful tool that supports top executives, project managers and engineers to develop and control the entire product development process. Secondly, it is impossible to redesign (or alter) the initial concept/part previously idealized by the customer. The collaboration in this kind of environment is much more constricted. In this way, IdeaMaker "intends to open itself to new markets [...] automotive sector requests high processes efficiencies [...] it squeezes the profit margins of its suppliers. [Other sectors] are less stressful... and the objective is to increase profit margins.” (IdeaMaker Project \& Sales Manager)

NextVision is the paradigm of the second tier suppliers for automotive first tier customers. The customer holds the final authority of the design that is a normal situation in automotive industry at this supply chain level. Moreover, continuous cost reduction during the production process (kaizen costing) is a demand of automotive customers.

This company totally leads its development and production; they have the fully knowledge of all engineering processes. However, if a Tier 2 supplier, such as NextVision, does not demonstrate competitiveness on a specific product, the customer has the right to change, due to the nature of the contracts which are protectionist, firstly of OEMs and, secondly of Tier 1. "It is necessary a robust and competent structure with very specialized staff as well as advanced processes and methodologies [...] The cost of having such structure fits perfectly on the technological environment of the automotive industry [...] which has the capacity to absorb those fixed costs." (NextVision Business Director) 
The company considers customers and suppliers essential parts of its strategy. This collaboration is fundamental for the smooth running of projects within this sector because they can bring important insights to the process of products development.

Thus, results highlight that only crisscrossing effective cost management practices with effective collaborative product development processes lead to successful interdependent buyer-supplier relationships as well as to the overall benefit of the supply chain. Consequently, synergetic alliances are achieved. Figure 1 schematizes a set of in/out organizational conditioning factors that were found to shape the effectiveness of strategic collaboration activities of the three Portuguese plastics injection moulding companies.

\section{Effective Synergy of Strategic Alliances in Product Development Process}

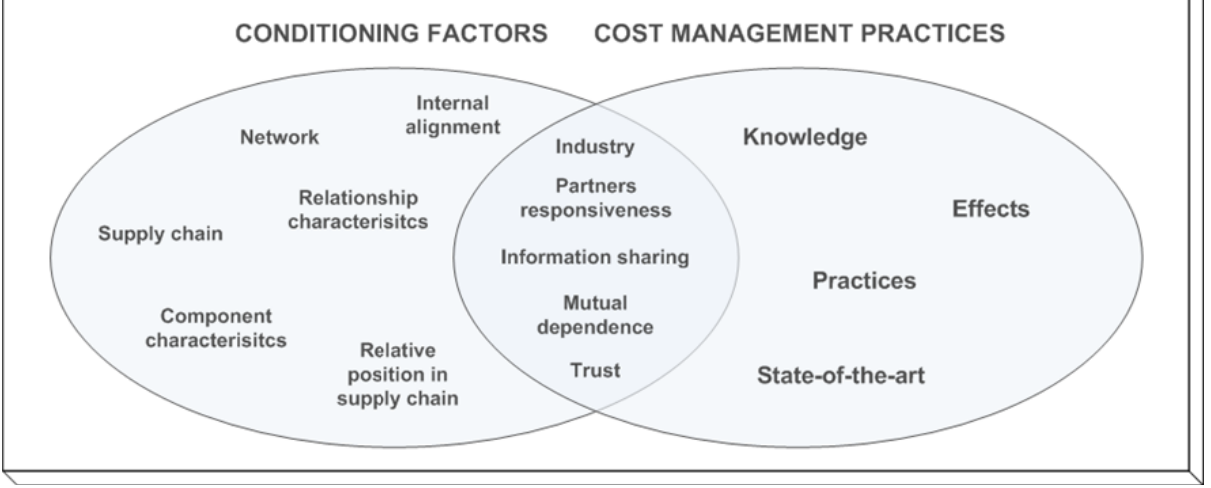

Fig. 1. Conditioning factors in collaborative cost management practices

Main conditioning factors that influence the level of collaboration among partners:

- Type of collaboration leadership (traditional: pull system / network: push system)

- Type of buyer industry (automotive / non-automotive)

- Component characteristics (complex / non-complex)

- Relative position in value chain (essentially OEMs, Tier 1 and Tier 2)

- Partners responsiveness (non-disclosure agreements and contracts)

- Inner personal characteristics (trustful top executive/managers)

The level of information sharing also influences strategic collaborations. This is the result of the mutual dependence levels and trust between customers and supplier. Effectively managing the suppliers' involvement in NPD projects implies the standardization of advanced methods and procedures throughout the value chain.

It is clear that strategic collaborations aim at improving the cost efficiency of the value chains. Accurate knowledge of IOCM state-of-the-art practices contributes to control all important dimensions in product development processes: technical, economic and social. On the literature a set of IOCM practices - which typically 
occur in early stages - were found: open-book, target costing, value engineering, design to cost, total cost of ownership, among others.

In our study we found that companies under study have been using along the product development process up to - and during - the production stage some of these techniques (e.g. target costing, value engineering, design to cost, and kaizen costing). The use of such practices has remarkable positive effects on internal organizational environment as well as on the entire value chain.

It was perceived from our qualitative approach that the accurate management of these practices leads to several benefits: trust improvement, decrease transaction costs, continuous productivity improvements, efficient cost control, profitable results, increase value to buyers and suppliers, competitive advantages, improve cost efficiency and sustainability of supply chains, high standards of efficiency and quality, and reduce risk. Total cost transparency, or sharing sensitive costs information seems, contrariwise, to be a non-total desirable consequence for the nonautomotive suppliers. This is contrary of the intrinsic philosophy behind the IOCM practices.

\section{Conclusions}

The three cases indicated that the involvement of several interlinked buyers and suppliers in the supply chain contributed for an effective cost reduction of the final product. Indeed, collaborative cost management practices are important in the relationship between supplier-buyer, because proposals and modifications made in product design and production processes by a company depend and have implications for operations management in the future.

The studied firms have been applying concurrent and collaborative engineering activities during NPD projects for different industries (e.g. automotive and others), which enable the production of parts and subassemblies (or subsystems) with higher value added. The automotive sector, its meticulousness and vicissitudes, pulls the organizations' skills and performance. Although the higher levels of exigency leading to lower profit margins, this sector is much more predictable and allows increasing the business reflectiveness, management skills, and engineering processes.

It was observed that collaboration levels are a function of companies' inner competencies and the characteristics/complexity of the product. Moreover, the industry type, i.e. the atmosphere of firm's interaction (relative position across the supply chain) and the environment in which the relationship takes place, also plays an important role on the collaboration levels among partners. For instance, the ISO/TS 16949 standard obliges, among many things, a high level of collaboration and cost sharing between buyers and suppliers.

Firms aiming at implementing this strategy effectively have to pay close attention to several contingency factors on the organizational level and properly manage supplier involvement on product development, product industrialization and parts supplying at production stage. 


\section{References}

1. Coad, A., Cullen, J.: Inter-Organisational Cost Management: Towards an Evolutionary Perspective. Management Accounting Research 17, 342-369 (2006)

2. Laaksonen, T., Jarimo, T., Kulmala, H.: Cooperative Strategies in Customer-Supplier Relationships: The Role of Interfirm Trust. International Journal of Production Economics 120, 79-87 (2009)

3. Cooper, R., Slagmulder, R.: Interorganizational Cost Management and Relational Context. Accounting, Organizations and Society 29, 1-26 (2004)

4. Kajuter, P., Kulmala, H.: Open-book accounting in networks, Potential Achievements and Reasons for Failures. Management Accounting Research 16, 179-204 (2005)

5. Agndal, H., Nilsson, U.: Interorganizational Cost Management in the Exchange Process. Management Accounting Research 20, 85-101 (2009)

6. Bechtel, C., Jayaram, J.: Supply chain management: a strategic perspective. International Journal of Logistics Management 8, 15-34 (1997)

7. Harmsen, H., Grunert, K., Bove, K.: Company competencies as a network: the role of product development. Journal of Product Innovation Management 17, 194-207 (2000)

8. Randall, T., Morgan, R., Morton, A.: Efficient versus responsive supply chain choice: an empirical examination of influential factors. Journal of Product Innovation Management 20, 430-443 (2003)

9. Narasimhan, R., Swink, M., Viswanathan, S.: On decisions for integration implementation: an examination of complementarities between product-process technology integration and supply chain integration. Decision Sciences 41, 355-372 (2010)

10. Halldorsson, A., Kotzab, H., Mikkola, J., Skjott-Larsen, T.: Complementary theories to supply chain management. Supply Chain Management: International Journal 12, 284-296 (2007)

11. Flynn, B., Flynn, E.: An exploratory study of the nature of cumulative capabilities. Journal of Operations Management 22, 439-457 (2004)

12. Hong, P., Kwon, H., Roh, J.: Implementation of strategic green orientation in supply chain: an empirical study of manufacturing firms. European Journal of Innovation Management 12, 512-532 (2009) 